\title{
Correction to: Letter to the editor Re: Cearns MD, Kommer M, Amato-Watkins A, Campbell E, Beez T, O'Kane R (2020) opening and closure of intraventricular neuroendoscopic procedures in infants under 1 year of age: institutional technique, case series and review of the literature
}

\author{
William B. Lo ${ }^{1}$ • Fardad T. Afshari $^{1}$ - Desiderio Rodrigues ${ }^{1}$ • Abhaya V. Kulkarni ${ }^{2}$ \\ Published online: 3 December 2020 \\ (C) Springer-Verlag GmbH Germany, part of Springer Nature 2020
}

\section{Correction to: Child's Nervous System}

https://doi.org/10.1007/s00381-020-04936-5

The published version of this article unfortunately contained an error. Unfortunately, the author noticed an error only after the proof was sent back to journal production. It is the second last sentence, "The superficial flaps act as an dural underlay, further augmenting the dural layer" instead of "The superficial flaps act as an extradural underlay, further augmenting the dural layer". This is quite an important anatomical description crucial to the letter. The author apologize for the inconvenience they have caused.

The original article has been corrected.

Publisher's note Springer Nature remains neutral with regard to jurisdictional claims in published maps and institutional affiliations.
The online version of the original article can be found at https://doi.org/ 10.1007/s00381-020-04936-5

William B. Lo

williamlo@doctors.org.uk

1 Department of Neurosurgery, Birmingham Children's Hospital, Birmingham B4 6NH, UK

2 Division of Neurosurgery, Hospital for Sick Children, University of Toronto, Toronto, Canada 